\title{
Mental health, smoking, harm reduction and quit attempts - a population survey in England
}

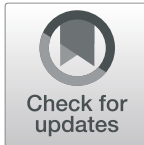

Leonie S. Brose ${ }^{1,2^{*}}$ (D), Jamie Brown ${ }^{2,3,4}$, Debbie Robson ${ }^{1,2}$ and Ann McNeill ${ }^{1,2}$

\begin{abstract}
Background: Tobacco control strategies have engendered overall declines in smoking; however, a large gap remains between people with and without mental health problems, causing substantial health inequalities. Population-level information on barriers and opportunities for improvements is scarce. We aimed to assess mental health status of cigarette smokers and recent ex-smokers ('past-year smokers') in England, and smoking and harm reduction behaviour and quit attempts by mental health status.

Methods: Data were collected from 5637 current and 434 recent ex-smokers in 2016/17 in household surveys of representative samples of adults. We calculated weighted prevalence of different indicators of mental health problem: a) ever diagnosis, b) none, moderate, serious past-month distress, c) past-year treatment. We compared weighted smoking status, cigarette type, dependence, motivation to stop smoking, cutting down, use of nicotine replacement therapy or e-cigarettes, short-term abstinence, and quit attempts according to mental health status.

Results: Among past-year smokers: $35.9 \%$ ever had a diagnosis; $24.3 \%$ had experienced moderate, an additional 9.7\% serious, past-month distress; $21.9 \%$ had had past-year treatment. Those with an indication of a mental health problem were more highly dependent and more likely to smoke roll-your-own cigarettes but also more likely to be motivated to stop smoking, to cut down, use nicotine replacement therapy or e-cigarettes and to have attempted to quit in the past year.
\end{abstract}

Conclusions: About a third of cigarette smokers in England have mental health problems. Interventions should address their increased dependence and leverage higher prevalence of harm reduction behaviours, motivation to stop and attempts to stop smoking.

Keywords: Tobacco smoking, Smoking cessation, Mental health, Electronic cigarettes, Harm reduction

\section{Background}

There are substantial inequalities in morbidity and premature mortality between individuals with mental health problems and those without and much of this inequality is due to smoking [1-3]. Tobacco control strategies have led to an overall decline in smoking

\footnotetext{
* Correspondence: leonie.brose@kcl.ac.uk

'Addictions, Institute of Psychiatry, Psychology and Neuroscience, King's

College London, 4 Windsor Walk, London SE5 8BB, UK

${ }^{2}$ SPECTRUM Consortium, UK

Full list of author information is available at the end of the article
}

prevalence in countries such as the UK and US, however, there remains a large gap in smoking prevalence between people with and without mental health problems. Among those with a common mental health disorder in England, smoking prevalence remains around $50 \%$ higher [4] and this increases further for more severe mental disorders [5]. Figures for the US similarly show an increased burden of smoking among those with mental health problems $[6,7]$. The relationship is complex but appears to be bidirectional $[8-10]$. 
Previous research has consistently shown that smokers with mental health problems on average smoke more heavily $[4,5,7]$ and extract more nicotine from each cigarette than those without mental health problems [5]. People with schizophrenia, bipolar disorder, depression and anxiety who smoke experience more severe symptoms and require higher doses of some psychotropic medicines than non-smokers [5]. Smoking is also associated with poorer treatment outcomes; compared with non-smokers with mental health problems, smokers with mental health problems spend longer time in hospital and less time out of hospital [11]. There is some evidence, mainly from the US, that smokers with mental health problems are as likely to make a quit attempt as other smokers [12] but cessation rates are lower. Successful quitting is associated with improved mental health, specifically reduced anxiety, depression and stress and increased psychological quality of life and positive affect [13]; additionally, for specific medications for severe mental illness, quitting may reduce the required dosage [5] and thus associated side effects.

Preventing the uptake of smoking, prompting more quit attempts and improving access to smoking cessation or harm reduction interventions are needed to reduce the excess burden of disease and premature mortality associated with smoking among people with mental health problems. Research about the effectiveness of smoking cessation interventions among smokers with severe mental health problems is promising $[14,15]$. However, advancement of smoking cessation for smokers with mental health problems is limited, particularly in England and the rest of the UK, by a lack of population level studies about smoking prevalence, motivation to quit, attempts to quit and harm reduction behaviours which are needed to quantify the need and identify barriers and opportunities for interventions.

This study aimed to answer the following questions:

1. What is the mental health status of current cigarette smokers and recent ex-smokers ("past-year smokers') in England?

2. What are the characteristics of smoking behaviour among past-year smokers with and without mental health problems?

3. What are the characteristics of harm reduction behaviour among current cigarette smokers with and without mental health problems?

4. What is the frequency of quit attempts in past-year smokers with and without mental health problems?

\section{Methods}

\section{Procedure}

The present study uses self-reported data from monthly cross-sectional household surveys of representative samples of the population of adults in England collected as part of the ongoing Smoking and Alcohol Toolkit Study. The methodology for the Toolkit Study has been described in detail by Fidler et al. [16] and to date, it has been used as the basis for approximately 85 peerreviewed publications. Briefly, each month (wave), a new sample of approximately 1700 adults aged 16 years or older in England completes a face-to-face computerassisted survey. After stratification by geo-demographic classification of population, small geographical areas containing approximately 300 households are allocated randomly to interviewers who visit households within the locality and conduct computer-assisted face-to-face interviews with one member of a household in those areas until a pre-specified quota tailored to the area is fulfilled. This form of sampling has benefits over conventional quota sampling, because the allocation of small areas to interviewers reduces the impact of selection bias resulting from the selection of properties [17]. Response rates cannot be calculated because of the lack of a definitive gross sample: all units fulfilling the criteria of a given quota are interchangeable within the areas. For the present study, measures of mental health were added to the survey for 24 monthly waves from January 2016 to December 2017.

\section{Measures}

All measures were self-reported. Generally, questions were completed in an interview with the interviewer recording the responses; the mental health questions were self-completed by the interviewee on a laptop following familiarisation using similar example questions.

Sociodemographic measures included age (16-24; 25$34 ; 35-44 ; 45-54 ; 55-64 ; 65$ and over), gender and occupational grade (coded $\mathrm{AB}$ for higher or intermediate managerial, administrative or professional occupation; C1 for Supervisory or clerical and junior managerial, administrative or professional; $\mathrm{C} 2$ for skilled manual workers; D for semi-skilled and unskilled manual workers; E for state pensioners, casual and lowest grade workers, unemployed with state benefits only [18]).

Smoking-related measures included smoking status, assessed using "Which of the following best applies to you? Please note we are referring to cigarettes and other kinds of tobacco that you set light to and NOT electronic or 'heat-not-burn' cigarettes. a) I smoke cigarettes (including hand-rolled) every day; b) I smoke cigarettes (including hand-rolled), but not every day; c) I do not smoke cigarettes at all, but I do smoke tobacco of some kind (e.g. pipe, cigar or shisha); d) I have stopped smoking completely in the last year; e) I stopped smoking completely more than a year ago; f) I have never been a smoker (i.e. smoked for a year or more)." Those who had stopped smoking more than a year ago (response e) 
or had never been smokers (f) were excluded as were the 186 smokers who reported currently smoking other tobacco products (c). Those selecting responses a or b were categorised as current smokers; current smokers and those who had stopped in the last year (d) were categorised as past-year smokers. Those who had stopped smoking may have included a small number of respondents who had smoked products other than cigarettes. Past-year cigarette smokers reported type of cigarette smoked (hand-rolled, manufactured or both), strengths of urges to smoke [19] and heaviness of smoking index (cigarettes per day and time to first cigarette [20]); current cigarette smokers also reported motivation to stop smoking [21] and average spend on tobacco per week.

Harm reduction measures for all past-year smokers included number of attempts to quit smoking in the past year and whether abstinence from smoking of one month or longer was achieved during the past year which was derived from questions about how long each of up to three quit attempts undertaken in the last year lasted before going back to smoking. Current smokers were additionally asked whether they were currently attempting to cut down on the number of cigarettes and whether they were currently using nicotine replacement therapy (NRT) or e-cigarettes/vaping products (EC) for cutting down, temporary abstinence or other reasons.

Mental health measures included three indicators of mental health problems:

1. Ever diagnosis: Participants were asked: "Since the age of 16, which of the following, if any, has a doctor or health professional ever told you that you had? Depression; Anxiety; Obsessive Compulsive Disorder; Panic Disorder or a phobia; Posttraumatic Stress Disorder; Psychosis; Personality Disorder; Attention Deficit Hyperactivity Disorder; An Eating Disorder; Alcohol Misuse or Dependence; Drug Use or Dependence; Problem Gambling; None of these; Don't know; Prefer not to say." Question wording was adapted from previous surveys [22, 23], the list of diagnoses based on a report on adult psychiatric morbidity in England [24]. Response options excluding the final three were presented in a randomised order. Individual diagnoses were dummy-coded. For analysis, a composite measure of 'Any diagnosis' was derived.

2. Past-month distress: Measured using the K6 screener for mental distress in the past 30 days [25, 26]: "During the past 30 days, about how often, if at all, did you feel ... nervous; hopeless; restless or fidgety; so depressed that nothing could cheer you up; that everything was an effort; worthless?" The options were presented in a randomised order and for each the respondent indicated one of the following: "All of the time (scored 4); Most of the time [3]; Some of the time [2]; A little of the time [1]; None of the time (0)"; these options were presented in this or the reverse order for the entire K6. Additional response options “Don't know; Prefer not to say" were provided. The K6 has been validated and used in a number of population surveys [25-35]. A sum score with a possible range from 0 to 24 was calculated and following common practice, scores of 13 and higher categorised as serious distress $[25,29]$. Some publications have additionally used a category of moderate distress (scores 5-12) [31] which was also used.

3. Past-year treatment: Respondents who selected any of the responses for ever diagnosis were asked for those they selected: "In the last 12 months, which of the following conditions, if any, have you had any treatment or taken any prescribed medication for?".

\section{Sample selection}

In 2016 and 2017, 40,831 adults were surveyed of whom 7651 were past-year (current and recent-ex) smokers who were asked the mental health questions. Smokers who exclusively smoked tobacco products (pipes, cigars) other than cigarettes were excluded $(n=186)$. Those who did not complete the mental health questions or selected 'don't know' or 'prefer not to say' in response to any of them were also excluded, leaving 6280 past-year smokers with information on mental health. Finally, those with missing data on any of the other variables included in the present analysis were excluded, leaving 6071 past-year smokers for the main analyses, of whom 5637 were current cigarette smokers and 434 recent exsmokers. Type of cigarette smoked was missing for 164, reducing the sample to 5907 past-year smokers and 5506 current cigarette smokers if type of cigarette was included in analysis.

\section{Analysis}

Past-year smokers who completed the mental health information were compared with those who did not complete the mental health information or responded don't know or prefer not to say.

To address research question 1 (mental health), weighted proportions were used to describe the prevalence of ever having had any mental health diagnosis since the age of 16 , the prevalence of moderate and serious distress in the past month and the prevalence of treatment for mental health problems in the past year overall and by diagnosis.

To address research question 2 (smoking behaviour by mental health), weighted proportions were calculated and chi-square statistics were used to compare smoking 
status, type of cigarette smoked, dependence (as measured using urges to smoke and heaviness of smoking) of past-year cigarette smokers with and without any diagnosis, with minimal, moderate and serious past-month distress and with and without past-year treatment. For chi-square tests, Cramer's V was used as effect size. Cramer's V can range from 0 (no association) to 1 (perfect association). Additionally, for current cigarette smokers, spend on tobacco was compared using analyses of variance (ANOVAs) and independent samples median tests.

To address research question 3 (harm reduction behaviour), weighted proportions for cutting down, using e-cigarettes, using NRT, using either e-cigarettes or NRT, motivation to stop smoking and having achieved at least one month of abstinence in the past year were calculated for current cigarette smokers and compared using chi-square statistics with Cramer's V as effect size.

To address research question 4 (quit attempts), the mean number of quit attempts made in the past year was compared among past-year smokers with and without mental health problems. A dichotomised version of this measure (at least one quit attempt versus none) was used to calculate prevalence and 95\% confidence intervals of having made at least one quit attempt and as outcome in logistic regressions assessing its association with ever diagnosis, past-month levels of distress and past-year treatment among past-year smokers. Unadjusted models were followed by models adjusting for socio-demographics. Additional models adjusted for motivation to stop smoking and type of cigarette; as this information can only be collected from current cigarette smokers, any quit attempt had been unsuccessful.

The analyses plan was pre-registered on the Open Science Framework (https://osf.io/9pbv8/). The following changes were made from the registration: Research question 1 was added to provide a fuller description of the population. The present research questions 2 and 3 were initially presented as a single research question. To increase consistency, smokers of other tobacco products such as pipes or cigars were excluded from all analysis.

\section{Results}

Non-completion of mental health information became slightly more likely with increasing age and was more likely for non-daily cigarette smokers and current NRT users, but differences were small (Supplementary file 1, Table S1).

\section{Mental health}

Overall, 35.9\% of past-year smokers reported ever having been diagnosed with at least one mental health problem since the age of $16,34.0 \%$ reported having experienced moderate $(24.3 \%)$ or serious distress $(9.7 \%)$ in the past month and $21.9 \%$ of the sample had received treatment for a mental health in the past year. Among those who had ever been diagnosed with a mental health problem, the most common diagnosis was depression, followed by anxiety (Supplementary file 2, Table S2). In the past year, $61.0 \%$ of those with a diagnosis had received treatment for this diagnosis, however, this ranged from $7.9 \%$ for problem gambling to $64.1 \%$ for psychosis (Supplementary file 2, Table S2). In general, indicators of mental health problems were more common among younger age groups, women and lower socio-economic groups (Table 1).

\section{Smoking}

About $7 \%$ of the sample reported having stopped smoking completely in the past year. Most participants were daily cigarette smokers, and there was little difference between those with and without mental health problems. Overall, about half smoked roll-your own exclusively (44.1\%) or alongside manufactured cigarettes (5.4\%) and this was more common among cigarette smokers with mental health problems. The vast majority of past-year smokers experienced at least some urges to smoke although few had high heaviness of smoking ratings. Stronger urges and heavier smoking were more common among those with mental health problems (Table 1).

Current cigarette smokers with data on spend available $(n=5421)$ on average spent $£ 22.61(\mathrm{SD}=17.09)$ per week on tobacco or cigarettes (median £20). This was lower among those with any diagnosis or distress, but not by treatment (Table 1), likely in part due to higher rates smoking roll-your own.

\section{Harm reduction}

Overall, $46.1 \%$ of smokers were cutting down, 19.4\% were using e-cigarettes and $8.5 \%$ nicotine replacement therapy (Table 1). All three harm reduction behaviours were more common among smokers with a mental health problem, albeit all with Cramer's $\mathrm{V} \leq 0.1$ (Table 1). About one in seven (14.4\%) reported motivation to stop smoking within the next three months. This was slightly more common among those with any indicator of mental health problems, with Cramer's V below 0.1 . (Table 1). In the last year, $12.9 \%$ had achieved at least one month of abstinence. This did not differ by ever diagnosis or past-year treatment but by level of distress; those with minimal distress were least likely and those with moderate distress most likely to have achieved a month of abstinence, again with Cramer's V below 0.1 (Table 1).

\section{Quit attempts}

Just under a third (32.5\%) of those who smoked in the past year had made at least one quit attempt in that 
Table 1 Sample description (weighted data) by indicator of mental health problem in past-year smokers and the subset of current smokers

\begin{tabular}{|c|c|c|c|c|c|c|c|c|c|c|c|c|}
\hline \multirow{2}{*}{\multicolumn{2}{|c|}{ Past-year cigarette smokers }} & \multirow{3}{*}{$\begin{array}{l}\text { All } \\
6071\end{array}$} & \multicolumn{3}{|c|}{ Ever diagnosis } & \multicolumn{4}{|c|}{ Past-month distress } & \multicolumn{3}{|c|}{ Past-year treatment } \\
\hline & & & \multirow{2}{*}{$\begin{array}{l}\text { No } \\
3904\end{array}$} & \multirow{2}{*}{$\begin{array}{l}\text { Yes } \\
2167\end{array}$} & \multirow[t]{2}{*}{ Test statistics } & \multirow{2}{*}{$\begin{array}{l}\text { Minimal } \\
3981\end{array}$} & \multirow{2}{*}{$\begin{array}{l}\text { Moderate } \\
1499\end{array}$} & \multirow{2}{*}{$\begin{array}{l}\text { Serious } \\
591\end{array}$} & \multirow[t]{2}{*}{ Test statistics } & \multirow{2}{*}{$\begin{array}{l}\text { No } \\
4742\end{array}$} & \multirow{2}{*}{$\begin{array}{l}\text { Yes } \\
1329\end{array}$} & \multirow{2}{*}{$\begin{array}{l}\text { Test } \\
\text { statistics }\end{array}$} \\
\hline Unweighted n & & & & & & & & & & & & \\
\hline \multirow[t]{6}{*}{ Age, $\%$} & $16-24$ & 18.8 & 18.4 & 19.6 & \multirow{6}{*}{$\begin{array}{l}x^{2}=87.89 \\
p<0.001 \\
V=0.118\end{array}$} & 15.1 & 25.9 & 26.1 & \multirow{6}{*}{$\begin{array}{l}x^{2}=207.65 \\
p<0.001 \\
V=0.128\end{array}$} & 18.7 & 19.2 & \multirow{6}{*}{$\begin{array}{l}x^{2}=74.83 \\
p<0.001 \\
V=0.109\end{array}$} \\
\hline & $25-34$ & 22.5 & 21.7 & 24.1 & & 21.8 & 23.7 & 24.6 & & 22.2 & 23.7 & \\
\hline & $35-44$ & 18.2 & 17.1 & 20.0 & & 17.6 & 19.2 & 19.2 & & 17.3 & 21.3 & \\
\hline & $45-54$ & 18.3 & 17.7 & 19.5 & & 19.3 & 15.7 & 18.1 & & 17.6 & 20.9 & \\
\hline & $55-64$ & 11.9 & 12.4 & 11.2 & & 13.4 & 9.0 & 9.6 & & 12.4 & 10.2 & \\
\hline & $\geq 65$ & 10.2 & 12.8 & 5.7 & & 12.8 & 6.5 & 2.3 & & 11.8 & 4.7 & \\
\hline \multirow[t]{2}{*}{ Gender, $\%{ }^{a}$} & Men & 52.4 & 57.6 & 43.0 & \multirow{2}{*}{$\begin{array}{l}x^{2}=124.73 \\
p<0.001 \\
V=0.141\end{array}$} & 55.5 & 48.2 & 41.2 & \multirow{2}{*}{$\begin{array}{l}X^{2}=58.32 \\
p<0.001 \\
V=0.096\end{array}$} & 56.2 & 38.7 & \multirow{2}{*}{$\begin{array}{l}X^{2}=132.23 \\
p<0.001 \\
V=0.145\end{array}$} \\
\hline & Women & 47.6 & 42.4 & 57.0 & & 44.5 & 51.8 & 58.8 & & 43.8 & 61.3 & \\
\hline \multirow{5}{*}{$\begin{array}{l}\text { Occupational } \\
\text { grade, } \%\end{array}$} & $A B$ & 14.9 & 16.0 & 13.1 & \multirow{5}{*}{$\begin{array}{l}x^{2}=209.54 \\
p<0.001 \\
V=0.182\end{array}$} & 16.3 & 13.2 & 10.4 & $x^{2}=235.35$ & 15.8 & 11.7 & $x^{2}=253.20$, \\
\hline & $\mathrm{C} 1$ & 24.5 & 25.1 & 23.5 & & 24.9 & 25.2 & 20.4 & $\begin{array}{l}p<0.001 \\
V=0.136\end{array}$ & 25.4 & 21.5 & $\begin{array}{l}p<0.001 \\
V=0.200\end{array}$ \\
\hline & C2 & 25.7 & 27.8 & 21.9 & & 27.7 & 23.0 & 18.6 & & 27.3 & 20.0 & \\
\hline & $\mathrm{D}$ & 20.2 & 21.2 & 18.3 & & 20.7 & 18.7 & 19.9 & & 20.5 & 18.8 & \\
\hline & $E$ & 14.7 & 9.9 & 23.2 & & 10.4 & 19.9 & 30.7 & & 11.0 & 27.9 & \\
\hline Smoking, \% & Daily cigs & 81.6 & 82.0 & 81.0 & $x^{2}=3.58$ & 82.7 & 78.8 & 82.1 & $x^{2}=11.44$ & 81.6 & 81.8 & $x^{2}=8.60$ \\
\hline & $\begin{array}{l}\text { Non-daily } \\
\text { cigs }\end{array}$ & 10.9 & 11.0 & 10.7 & $\begin{array}{l}p=0.167 \\
V=0.024\end{array}$ & 10.3 & 12.6 & 10.8 & $\begin{array}{l}p=0.022 \\
V=0.030\end{array}$ & 11.3 & 9.3 & $\begin{array}{l}p=0.014 \\
V=0.037\end{array}$ \\
\hline & $\begin{array}{l}\text { Stopped last } \\
\text { year }\end{array}$ & 7.5 & 7.0 & 8.3 & & 7.0 & 8.7 & 7.2 & & 7.1 & 8.8 & \\
\hline Type of & Manufactured & 50.4 & 56.2 & 40.2 & $x^{2}=146.15$ & 55.3 & 43.6 & 34.1 & $x^{2}=131.67$ & 53.6 & 39.3 & $x^{2}=87.92$ \\
\hline cigarette, \% & $\begin{array}{l}\text { Roll-your- } \\
\text { own }\end{array}$ & 44.1 & 38.8 & 53.7 & $\begin{array}{l}p<0.001 \\
V=0.154\end{array}$ & 40.0 & 50.1 & 57.8 & $\begin{array}{l}p<0.001 \\
V=0.103\end{array}$ & 41.5 & 53.6 & $\begin{array}{l}p<0.001 \\
V=0.120\end{array}$ \\
\hline & Mix & 5.4 & 5.0 & 6.1 & & 4.7 & 6.3 & 8.1 & & 4.9 & 7.2 & \\
\hline Urges to smoke, & None & 16.9 & 18.9 & 13.5 & $x^{2}=117.41$ & 18.4 & 14.8 & 12.6 & $x^{2}=179.27$ & 18.2 & 12.3 & $x^{2}=111.32$ \\
\hline$\%$ & 1 & 16.3 & 17.4 & 14.4 & $\begin{array}{l}p<0.001 \\
V=0.136\end{array}$ & 17.7 & 14.4 & 11.7 & $\begin{array}{l}p<0.001 \\
V=0.12\end{array}$ & 17.0 & 13.8 & $\begin{array}{l}P<0.001 \\
V=0.133\end{array}$ \\
\hline & 2 & 43.3 & 43.6 & 42.6 & & 44.1 & 43.6 & 36.7 & & 43.7 & 41.9 & \\
\hline & 3 & 17.3 & 15.8 & 20.0 & & 15.6 & 19.2 & 24.0 & & 16.2 & 21.1 & \\
\hline & 4 & 4.5 & 3.4 & 6.4 & & 3.2 & 5.6 & 10.4 & & 3.6 & 7.5 & \\
\hline & 5 & 1.7 & 0.9 & 3.0 & & 1.0 & 2.3 & 4.6 & & 1.2 & 3.4 & \\
\hline HSI, \% & $\operatorname{Low}(<4)$ & 87.5 & 90.4 & 82.4 & $x^{2}=84.35$ & 89.8 & 85.2 & 77.7 & $x^{2}=82.78$ & 89.4 & 80.7 & $x^{2}=75.31$ \\
\hline & High (4+) & 12.5 & 9.6 & 17.6 & $\begin{array}{l}P<0.001 \\
V=0.116\end{array}$ & 10.2 & 14.8 & 22.3 & $\begin{array}{l}P<0.001 \\
V=0.114\end{array}$ & 10.6 & 19.3 & $\begin{array}{l}P<0.001 \\
V=0.109\end{array}$ \\
\hline$\underset{\%}{\geq 1}$ b quit attempt, & Yes & 32.5 & 30.4 & 36.2 & $\begin{array}{l}x^{2}=22.00 \\
p<0.001 \\
v=0.059\end{array}$ & 29.6 & 37.7 & 38.8 & $\begin{array}{l}x^{2}=46.28 \\
p<0.001 \\
V=0.086\end{array}$ & 30.8 & 38.3 & $\begin{array}{l}x^{2}=27.05 \\
p<0.001 \\
v=0.065\end{array}$ \\
\hline $\begin{array}{l}\text { Abstinence } \geq 1 \\
\text { month, } \%\end{array}$ & Yes & 12.9 & 12.3 & 13.8 & $\begin{array}{l}x^{2}=3.01 \\
p=0.083 \\
V=0.022\end{array}$ & 11.6 & 16.1 & 13.4 & $\begin{array}{l}x^{2}=20.39 \\
p<0.001 \\
v=0.057\end{array}$ & 12.5 & 14.1 & $\begin{array}{l}x^{2}=2.40 \\
p=0.122 \\
V=0.019\end{array}$ \\
\hline Current cigarette & smokers & & & & & & & & & & & \\
\hline Unweighted n & & 5637 & 3646 & 1991 & & 3708 & 1381 & 548 & & 4420 & 1217 & \\
\hline MTSS \% & In $\leq 3$ months & 14.4 & 13.3 & 16.3 & $\begin{array}{l}X^{2}=9.79 \\
p=0.002 \\
V=0.041\end{array}$ & 13.0 & 17.7 & 15.6 & $\begin{array}{l}X^{2}=19.30 \\
p<0.001 \\
V=0.057\end{array}$ & 13.6 & 17.3 & $\begin{array}{l}X^{2}=11.15 \\
p=0.001 \\
V=0.044\end{array}$ \\
\hline Cutting down, \% & Yes & 46.1 & 43.1 & 51.4 & $\begin{array}{l}x^{2}=37.12 \\
p<0.001 \\
V=0.080\end{array}$ & 42.8 & 52.2 & 53.3 & $\begin{array}{l}x^{2}=49.39 \\
p<0.001 \\
V=0.092\end{array}$ & 44.5 & 52.0 & $\begin{array}{l}x^{2}=22.57 \\
p<0.001 \\
V=0.062\end{array}$ \\
\hline
\end{tabular}


Table 1 Sample description (weighted data) by indicator of mental health problem in past-year smokers and the subset of current smokers (Continued)

\begin{tabular}{|c|c|c|c|c|c|c|c|c|c|c|c|c|}
\hline & \multirow{3}{*}{$\begin{array}{l}\text { All } \\
6071\end{array}$} & \multicolumn{3}{|c|}{ Ever diagnosis } & \multicolumn{4}{|c|}{ Past-month distress } & \multicolumn{3}{|c|}{ Past-year treatment } \\
\hline Past-year cigarette & smokers & & \multirow{2}{*}{$\begin{array}{l}\text { No } \\
3904\end{array}$} & \multirow{2}{*}{$\begin{array}{l}\text { Yes } \\
2167\end{array}$} & \multirow[t]{2}{*}{ Test statistics } & \multirow{2}{*}{$\begin{array}{l}\text { Minimal } \\
3981\end{array}$} & \multirow{2}{*}{$\begin{array}{l}\text { Moderate } \\
1499\end{array}$} & \multirow{2}{*}{$\begin{array}{l}\text { Serious } \\
591\end{array}$} & \multirow[t]{2}{*}{ Test statistics } & \multirow{2}{*}{$\begin{array}{l}\text { No } \\
4742\end{array}$} & \multirow{2}{*}{$\begin{array}{l}\text { Yes } \\
1329\end{array}$} & \multirow{2}{*}{$\begin{array}{l}\text { Test } \\
\text { statistics }\end{array}$} \\
\hline Unweighted $n$ & & & & & & & & & & & & \\
\hline Current NRT, \% & Yes & 8.5 & 7.5 & 10.5 & $\begin{array}{l}x^{2}=15.60 \\
p<0.001 \\
V=0.052\end{array}$ & 7.6 & 10.0 & 11.2 & $\begin{array}{l}x^{2}=13.33 \\
p=0.001 \\
V=0.048\end{array}$ & 7.6 & 11.8 & $\begin{array}{l}x^{2}=22.26 \\
p<0.001 \\
V=0.062\end{array}$ \\
\hline Current EC, \% & Yes & 19.4 & 17.1 & 23.5 & $\begin{array}{l}x^{2}=34.78 \\
p<0.001 \\
V=0.077\end{array}$ & 16.6 & 25.5 & 23.0 & $\begin{array}{l}x^{2}=57.95 \\
p<0.001 \\
V=0.100\end{array}$ & 18.1 & 23.9 & $\begin{array}{l}x^{2}=21.10 \\
p<0.001 \\
V=0.060\end{array}$ \\
\hline $\begin{array}{l}\text { Current NRT or } \\
\mathrm{EC}, \%\end{array}$ & Yes & 25.4 & 22.6 & 30.5 & $\begin{array}{l}x^{2}=44.64 \\
p<0.001 \\
V=0.087\end{array}$ & 22.3 & 31.6 & 30.6 & $\begin{array}{l}x^{2}=56.02 \\
p<0.001 \\
V=0.098\end{array}$ & 23.5 & 32.4 & $\begin{array}{l}x^{2}=41.13 \\
p<0.001 \\
V=0.084\end{array}$ \\
\hline $\begin{array}{l}\text { Weekly spend } \\
\text { Mean (SD) }{ }^{b}\end{array}$ & $\mathfrak{E}$ & $\begin{array}{l}22.6 \\
(17.1)\end{array}$ & $\begin{array}{l}23.3 \\
(17.3)\end{array}$ & $\begin{array}{l}21.4 \\
(16.7)\end{array}$ & $\begin{array}{l}F=15.30 \\
p<0.001\end{array}$ & $\begin{array}{l}23.3 \\
(17.3)\end{array}$ & $\begin{array}{l}21.5 \\
(16.8)\end{array}$ & $\begin{array}{l}20.8 \\
(16.2)\end{array}$ & $\begin{array}{l}F=8.75 \\
p<0.001\end{array}$ & $\begin{array}{l}22.7 \\
(17.1)\end{array}$ & $\begin{array}{l}22.3 \\
(17.0)\end{array}$ & $\begin{array}{l}F=0.57 \\
p=0.45\end{array}$ \\
\hline $\begin{array}{l}\text { Weekly spend } \\
\text { Median }\end{array}$ & $\mathfrak{E}$ & 20 & 20 & 16 & $p<0.001$ & 20 & 17 & 15 & $p<0.001$ & 20 & 17 & $p=0.33$ \\
\hline
\end{tabular}

MTSS Motivation to stop smoking

${ }^{a}$ The provided third option was not used by anyone in the included sample

${ }^{\mathrm{b}}$ Type of cigarette missing unweighted $n=164$, weekly spend missing unweighted $n=216$

'The median number of quit attempts was 0 for all groups; the mean number of quit attempts overall was $0.59(S D=3.10)$, this was similar for those with ( $M=$ $0.67 ; \mathrm{SD}=3.00)$ and without diagnosis $(\mathrm{M}=0.55, \mathrm{SD}=3.15 ; \mathrm{F}(1,6316)=2.13, p=0.14)$, with $(\mathrm{M}=0.71, \mathrm{SD}=2.82)$ and without past-year treatment $(\mathrm{M}=0.56, \mathrm{SD}=$ 3.17; $F(1,6316)=2.42, p=0.112$ ) and differed slightly across levels of distress (minimal: $M=0.51, S D=3.08$, moderate: $M=0.76, S D=3.55$, serious: $M=0.70, S D=$ $1.66 ; F(2,6315)=3.93, p=0.02)$

time. In unadjusted analysis, prevalence of having made at least one quit attempt was higher among past-year smokers with any diagnosis (36.2, 95\% CI: 34.2-38.1; unadjusted $\mathrm{OR}=1.36,95 \% \mathrm{CI}: 1.22-1.53, p<0.001)$ than among those without diagnosis (30.4, 95\% CI: 29.0 31.8). Prevalence of having made at least one quit attempt increased with distress, from $29.6 \%$ (95\% CI: 28.2-31.0) among those with no or minimal distress through $37.7 \%$ (95\% CI: 35.3-40.1; unadjusted $\mathrm{OR}=$ 1.45, 95\% CI: $1.28-1.64, p<0.001)$ among those with moderate distress to $38.8 \%$ (95\% CI: 35.0-42.7; unadjusted $\mathrm{OR}=1.54,95 \% \mathrm{CI}: 1.28-1.84, \mathrm{p}<0.001)$ among those with serious distress. Treatment in the past year was also associated with higher prevalence of having made a quit attempt (38.3\%; 95\% CI: 35.7-40.8; unadjusted $\mathrm{OR}=1.44,95 \%$ CI: 1.27-1.64, $\mathrm{p}<0.001)$ compared with not having had treatment (30.8\%; 95\% CI: 29.6-32.1). The strength of these associations remained very similar in adjusted analysis (Table 2). When including only current smokers, smokers with any diagnosis, past-month distress or past-year treatment were also more likely to have made a quit attempt than smokers without these indicators of a mental health problem (Table 2).

\section{Discussion}

Different indicators of mental health problems showed that substantial proportions of past-year smokers in England have mental health problems. Just over a third reported ever having had a diagnosis of a mental health

Table 2 Adjusted associations with having made at least 1 quit attempt in the past year by mental health diagnosis, level of pastmonth distress and past-year treatment for a mental health problem (unweighted data)

\begin{tabular}{|c|c|c|c|c|c|c|c|c|c|}
\hline & & \multicolumn{4}{|c|}{$\boldsymbol{n}=6071$ past-year cigarette smokers } & \multicolumn{4}{|c|}{$\boldsymbol{n}=5506$ current smokers } \\
\hline & & AOR & $95 \% \mathrm{Cl}$ & $95 \% \mathrm{Cl}$ & $p$ & AOR & $95 \% \mathrm{Cl}$ & $95 \% \mathrm{Cl}$ & $p$ \\
\hline \multirow[t]{2}{*}{ Any mental health diagnosis } & No & 1 & & & & 1 & & & \\
\hline & Yes & 1.32 & 1.17 & 1.48 & $<0.001$ & 1.25 & 1.09 & 1.43 & 0.001 \\
\hline \multirow[t]{3}{*}{ Past-month distress } & None/minimal & 1 & & & & 1 & & & \\
\hline & Moderate & 1.41 & 1.24 & 1.60 & $<0.001$ & 1.35 & 1.17 & 1.57 & $<0.001$ \\
\hline & Serious & 1.51 & 1.25 & 1.81 & $<0.001$ & 1.51 & 1.22 & 1.87 & $<0.001$ \\
\hline \multirow[t]{2}{*}{ Past-year treatment } & No & 1 & & & & 1 & & & \\
\hline & Yes & 1.41 & 1.24 & 1.61 & $<0.001$ & 1.37 & 1.18 & 1.60 & $<0.001$ \\
\hline
\end{tabular}

Separate models for 1. Any mental health diagnosis, 2. Level of past-month distress, 3. Past-year treatment for any mental health problem For past-year cigarette smokers adjusted for age, gender and occupational grade

For current smokers adjusted for age, gender, occupational grade, motivation to stop smoking and type of cigarette 
problem and around $60 \%$ of them had received treatment in the last year, suggesting an ongoing issue which was also indicated by just over a third experiencing moderate or serious mental distress in the past month. Those with an indication of a mental health problem were more highly dependent and more likely to smoke roll-your-own cigarettes. Cigarette smokers with a mental health problem were however more likely to be motivated to stop smoking and to engage in harm reduction behaviours such as use of e-cigarettes or NRT. Past-year smokers with mental health problems were more likely to have made at least one quit attempt in the past year and this remained true when including only current smokers (i.e. where any quit attempts had been unsuccessful). Yet, there was little difference by mental health in having achieved at least short-term abstinence among all past-year smokers, suggesting that quit attempts may be less successful in those with mental health problems.

The prevalence of mental health problems found in this population survey is in line with previous estimates that $30 \%$ of smokers in the UK have evidence of mental disorder [5] and an estimate that $27.4 \%$ of adults in England have ever been diagnosed with a common mental health problem (generalised anxiety disorder, depressive episode, obsessive compulsive disorder, phobias, panic disorder [36], omitting groups of less common diagnoses included in the present estimate). The level of moderate and severe distress found in past-year smokers in England is similar to those from a household survey in the US which found that in 2015, 25.8\% of current cigarette smokers had moderate and $9.4 \%$ serious distress in the past month [12]. Both a US survey [12, 30] and the present survey found that those with psychological distress were more likely to have made at least one quit attempt in the past year. The present finding that those with a mental health problem are at least as likely to be motivated to stop smoking is in line with earlier findings which used different measures to measure related constructs [4, 30, 37]. Previous research from the US found that current cigarette smokers with mental health problems were not statistically more likely to be using electronic cigarettes, this is in contrast to the present findings [38, 39].

The present study had several limitations. Timing or causality of events cannot be established; it could for example be argued that an unsuccessful quit attempt in the past-year could have increased distress and even increased the need for treatment for a mental health problem. However, associations were very similar for the different indicators of mental health problems, making this direction of causality appear less likely. All measures were self-reported; more comprehensive instruments may have differed in their detection of mental health problems. Because the survey is a household survey, it excludes people who are too unwell to take part or in healthcare institutions, thereby excluding those with the most severe mental health problem. Because respondents were asked to select the single option that best describes their smoking, use of other tobacco products such as pipes, cigars or shisha remained unreported among cigarette smokers. However, a strength is that data came from a long-standing established population survey and a sample representative of the adult population in England.

The present study is the first to provide detailed population-level evidence on motivation to quit smoking, attempts to do so and harm reduction behaviours of smokers in England by mental health status. It is also the first to report that smokers with a mental health problem are more likely to engage in harm reduction behaviours compared to those without.

Some implications for policy and clinical practice can be drawn from the findings. The relatively higher levels of motivation, attempts to stop smoking and harm reduction behaviours such as e-cigarette use among smokers with mental health problems compared to those without should be capitalised on by clinicians to reduce the burden from smoking. Specific challenges such as higher dependence on tobacco need to be addressed by making effective support available. A combination of behavioural support and medication is most effective in the wider population of smokers and has been shown to be effective for smokers with severe mental illness [14, 15] and for smokers with and without mental health problems making quit attempts [40]. In quit attempts and accompanied by behavioural support, e-cigarettes have been shown to be more effective than NRT [41]. In the Smoking Toolkit Study, they were also associated with increased success rates for smokers with and without mental health problems [40]. Additionally, smaller studies in smokers with severe mental illness who were not interested in quitting found that substantial proportions reduced their smoking by at least $50 \%$ when supplied with e-cigarettes [42, 43]. Clinicians should ensure that patients (both inpatient and community) have their smoking status identified and recorded in health care records. All smokers irrespective of their mental health status should be advised about the most effective way to quit and either provided with treatment or referred for specialist stop smoking support [44]. Ensuring harm reduction strategies are accessible should also be considered. Recently in England, the National Health Service has committed to funding tobacco treatment services for all smokers admitted to hospital, including the option to switch to e-cigarettes for mental health patients [45].

Future research needs to assess associations for specific mental health problems or groups of problems should also be assessed in addition to a catch-all category of any diagnosis. 


\section{Conclusions}

About a third of smokers in England have mental health problems. This population is more likely to be young, female and from lower socio-economic groups. They are more dependent on tobacco smoking but also more likely to engage in harm reduction behaviours, more motivated and more likely to attempt to stop smoking. Interventions should address their increased dependence but also leverage the higher prevalence of harm reduction behaviours, motivation to stop smoking and attempts to stop smoking in this population.

\section{Supplementary information}

Supplementary information accompanies this paper at https://doi.org/10. 1186/s12889-020-09308-x

Additional file 1. Supplementary file 1: Table S1. Comparison of pastyear smokers who completed the mental health information and those who terminated the survey prior to the section or responded don't know or prefer not to say.

Additional file 2. Supplementary file 2: Table S2. Weighted prevalence of individual diagnosis and past-year treatment for each diagnosis.

\section{Abbreviations}

ANOVA: Analysis of variance; Cl: Confidence interval; NRT: Nicotine replacement therapy; OR: Odds ratio; UK: United Kingdom; US: United States of America

\section{Acknowledgements}

We thank all survey participants. We thank Professor Robert West for his contribution to the analysis plan.

\section{Authors' contributions}

All authors (LSB, JB, DR, AMcN) contributed to the design of the work, interpretation of the data, approved the submitted version and are accountable for the work. LSB conducted the data analysis and drafted the article, JB, DR \& AMCN revised it. The author(s) read and approved the final manuscript.

\section{Funding}

This work was supported by a Cancer Research UK Fellowship awarded to LSB (C52999/A19748). For data collection for the Smoking Toolkit Study, Cancer Research UK is the main contributor (C1417/A22962), but the UK Department of Health, Pfizer, GlaxoSmithKline and Johnson and Johnson have also all contributed funding. JB receives support from CRUK (C1417) A22962)

All authors are members of SPECTRUM, a consortium supported by the UK Prevention Research Partnership (MR/S037519/1), which is funded by the British Heart Foundation, Cancer Research UK, Chief Scientist Office of the Scottish Government Health and Social Care Directorates, Engineering and Physical Sciences Research Council, Economic and Social Research Council, Health and Social Care Research and Development Division (Welsh Government), Medical Research Council, National Institute for Health Research, Natural Environment Research Council, Public Health Agency (Northern Ireland), The Health Foundation and the Wellcome Trust. The funders had no role on the study design, analysis or interpretation of the data, wiring of the report or decision to submit the paper for publication. Professor McNeill is a National Institute for Health Research (NIHR) Senior Investigator. The views expressed in this article are those of the authors and not necessarily those of the NIHR, or the Department of Health and Social Care.

\section{Availability of data and materials}

All authors have had access to the data. The datasets analysed during the current study are available from the corresponding author on reasonable request.

\section{Ethics approval and consent to participate}

Ethics approval for the Toolkit Study was originally granted by the University College London Ethics Committee (ID 0498/001). Addition of the mental health questions to the STS was approved by the University College London Research Ethics Committee (ID: 2808/005). All participants provided informed verbal consent, which was approved by the ethics committee.

\section{Consent for publication}

Not applicable.

\section{Competing interests}

The authors declare no competing interests.

\section{Author details}

${ }^{1}$ Addictions, Institute of Psychiatry, Psychology and Neuroscience, King's College London, 4 Windsor Walk, London SE5 8BB, UK. ${ }^{2}$ SPECTRUM Consortium, UK. ${ }^{3}$ Research Department of Clinical, Educational and Health Psychology, University College London, 1-19 Torrington Place, London WC1E 7HB, UK. ${ }^{4}$ Department of Epidemiology and Public Health, University College London, 1-19 Torrington Place, London WC1E 7HB, UK.

Received: 27 February 2020 Accepted: 28 July 2020

Published online: 14 August 2020

\section{References}

1. Tam J, Warner KE, Meza R. Smoking and the reduced life expectancy of individuals with serious mental illness. Am J Prev Med. 2016:51(6):958-66.

2. Wahlbeck K, Westman J, Nordentoft M, Gissler M, Laursen TM. Outcomes of Nordic mental health systems: life expectancy of patients with mental disorders. Brit J Psych. 2011;199(6):453-8.

3. Lawrence D, Hancock KJ, Kisely S. The gap in life expectancy from preventable physical illness in psychiatric patients in Western Australia: retrospective analysis of population based registers. BMJ. 2013;346:f2539.

4. Richardson S, McNeill A, Brose LS. Smoking and quitting behaviours by mental health conditions in Great Britain (1993-2014). Addict Behav. 2019; 90:14-9.

5. Royal College of Physicians, Royal College of Psychiatrists. Smoking and mental health. London: RCP; 2013.

6. Smith PH, Chhipa M, Bystrik J, Roy J, Goodwin RD, McKee SA. Cigarette smoking among those with mental disorders in the US population: 2012 2013 update. Tob Control. 2020;29(1):29-35.

7. Cook BL, Wayne GF, Kafali EN, Liu Z, Shu C, Flores M. Trends in smoking among adults with mental illness and association between mental health treatment and smoking cessation. JAMA. 2014;311(2):172-82.

8. Breslau N, Peterson EL, Schultz LR, Chilcoat HD, Andreski P. Major depression and stages of smoking. A longitudinal investigation. Arch Gen Psychiatry. 1998:55(2):161-6.

9. Johnson JG, Cohen P, Pine DS, Klein DF, Kasen S, Brook JS. Association between cigarette smoking and anxiety disorders during adolescence and early adulthood. JAMA. 2000;284(18):2348-51.

10. Lipari RN, Van Horn S. Smoking and mental illness among adults in the United States. Rockville (MD): The CBHSQ Report; 2013.

11. Prochaska JJ, Hall SE, Delucchi K, Hall SM. Efficacy of initiating tobacco dependence treatment in inpatient psychiatry: a randomized controlled trial. Am J Public Health. 2014;104(8):1557-65.

12. Kulik MC, Glantz SA. Softening Among U.S. Smokers with psychological distress: more quit attempts and lower consumption as smoking drops. Am J Prev Med. 2017:53(6):810-7.

13. Taylor G, McNeill A, Girling A, Farley A, Lindson-Hawley N, Aveyard P. Change in mental health after smoking cessation: systematic review and meta-analysis. BMJ. 2014;348:g1151.

14. Gilbody S, Peckham E, Bailey D, Arundel C, Heron P, Crosland S, et al. Smoking cessation for people with severe mental illness (SCIMITAR+): a pragmatic randomised controlled trial. Lancet Psychiat. 2019;6(5):379-90,

15. Peckham E, Brabyn S, Cook L, Tew G, Gilbody S. Smoking cessation in severe mental ill health: what works? An updated systematic review and meta-analysis. BMC Psychiatry. 2017;17(1):252.

16. Fidler JA, Shahab L, West O, Jarvis MJ, McEwen A, Stapleton JA, et al. 'The smoking toolkit study': a national study of smoking and smoking cessation in England. BMC Public Health. 2011;11:479. 
17. de Vaus DA. Surveys in social research. 5th ed. Crows Nest: Allen \& Unwin; 2002.

18. National Readership Survey. National Readership Survey social-grades. www. nrs.co.uk/nrs-print/lifestyle-and-classification-data/social-grade. 2016.

19. Fidler JA, Shahab L, West R. Strength of urges to smoke as a measure of severity of cigarette dependence: comparison with the Fagerstrom test for nicotine dependence and its components. Addiction. 2011;106(3):631-8.

20. Kozlowski LT, Porter CQ, Orleans CT, Pope MA, Heatherton T. Predicting smoking cessation with self-reported measures of nicotine dependence: FTQ, FTND, and HSI. Drug Alcohol Depend. 1994;34(3):211-6.

21. Kotz D, Brown J, West R. Predictive validity of the motivation to stop scale (MTSS): a single-item measure of motivation to stop smoking. Drug Alcohol Depend. 2013;128(1-2):15-9.

22. Morris CD, Burns EK, Waxmonsky JA, Levinson AH. Smoking cessation behaviors among persons with psychiatric diagnoses: results from a population-level state survey. Drug Alcohol Depend. 2014;136:63-8.

23. The NHS Information Centre. Adult psychiatric morbidity in England, 2007 results of a household survey. Appendices and glossary. Leeds: The NHS Information Centre; 2009

24. The NHS Information Centre for health and social care. Adult psychiatric morbidity in England, 2007. Results of a household survey. Leeds: The NHS Information Centre; 2009

25. Kessler RC, Barker PR, Colpe LJ, Epstein JF, Gfroerer JC, Hiripi E, et al. Screening for serious mental illness in the general population. Arch Gen Psychiatry. 2003;60(2):184-9.

26. Kessler RC, Green JG, Gruber MJ, Sampson NA, Bromet E, Cuitan M, et al. Screening for serious mental illness in the general population with the K6 screening scale: results from the WHO world mental health (WMH) survey initiative. Int J Meth Psych Res. 2010;19(Suppl 1):4-22.

27. Aldworth J, Colpe LJ, Gfroerer JC, Novak SP, Chromy JR, Barker PR, et al. The National Survey on drug use and health mental health surveillance study: calibration analysis. Int J Meth Psych Res. 2010;19(Suppl 1):61-87.

28. Furukawa TA, Kessler RC, Slade T, Andrews G. The performance of the K6 and $\mathrm{K} 10$ screening scales for psychological distress in the Australian National Survey of mental health and well-being. Psychol Med. 2003;33(2): 357-62.

29. Kessler RC, Andrews G, Colpe LJ, Hiripi E, Mroczek DK, Normand SL, et al. Short screening scales to monitor population prevalences and trends in non-specific psychological distress. Psychol Med. 2002;32(6):959-76.

30. Lawrence D, Mitrou F, Zubrick SR. Non-specific psychological distress, smoking status and smoking cessation: United States National Health Interview Survey 2005. BMC Public Health. 2011;11:256.

31. Prochaska JJ, Sung HY, Max W, Shi Y, Ong M. Validity study of the K6 scale as a measure of moderate mental distress based on mental health treatment need and utilization. I Int J Meth Psych Res. 2012;21(2):88-97.

32. Rush B, Castel S, Brands B, Toneatto T, Veldhuizen S. Validation and comparison of diagnostic accuracy of four screening tools for mental disorders in people seeking treatment for substance use disorders. J Subst Abus Treat. 2013;44(4):375-83.

33. Streck JM, Weinberger AH, Pacek LR, Gbedemah M, Goodwin RD. Cigarette smoking quit rates among persons with serious psychological distress in the United States from 2008-2016: are mental health disparities in cigarette use increasing? Nicotine Tob Res. 2020;22(1):130-4.

34. Cornelius BL, Groothoff JW, van der Klink JJ, Brouwer S. The performance of the $\mathrm{K} 10, \mathrm{~K} 6$ and GHQ-12 to screen for present state DSM-IV disorders among disability claimants. BMC Public Health. 2013;13:128.

35. Swartz JA, Lurigio AJ. Screening for serious mental illness in populations with co-occurring substance use disorders: performance of the K6 scale. J Subst Abus Treat. 2006;31(3):287-96.

36. McManus S, Bebbington P, Jenkins R, Brugha T, editors. Mental health and wellbeing in England: adult psychiatric morbidity survey 2014. Leeds: NHS Digital; 2016.

37. Siru R, Hulse GK, Tait RJ. Assessing motivation to quit smoking in people with mental illness: a review. Addiction. 2009:104(5):719-33.

38. Spears CA, Jones DM, Weaver SR, Pechacek TF, Eriksen MP. Use of Electronic Nicotine Delivery Systems among Adults with Mental Health Conditions, 2015. Int J Environ Res Public Health. 2016;14(1):10

39. Cummins SE, Zhu SH, Tedeschi GJ, Gamst AC, Myers MG. Use of e-cigarettes by individuals with mental health conditions. Tob Control. 2014;23(Suppl 3): iii48-53.
40. Brose LS, Brown J, McNeill A. Mental health and smoking cessation-a population survey in England. BMC Med. 2020;18(1):161.

41. Hajek P, Phillips-Waller A, Przulj D, Pesola F, Myers Smith K, Bisal N, et al. A randomized trial of E-cigarettes versus nicotine-replacement therapy. $\mathrm{N}$ Engl J Med. 2019;380(7):629-37.

42. Caponnetto P, Auditore R, Russo C, Cappello GC, Polosa R. Impact of an electronic cigarette on smoking reduction and cessation in schizophrenic smokers: a prospective 12-month pilot study. Int J Environ Res Public Health. 2013;10(2):446-61.

43. Hickling LM, Perez-lglesias R, McNeill A, Dawkins L, Moxham J, Ruffell T, et al. A pre-post pilot study of electronic cigarettes to reduce smoking in people with severe mental illness. Psychol Med. 2019;49(6):1033-40.

44. National Institute for Health and Care Excellence. Stop smoking interventions and services. https://www.nice.org.uk/guidance/ng92. 2018.

45. NHS England. The NHS Long Term Plan. 2019. https://www.longtermplan. nhs.uk/. ;accessed 20 Aug 2019.

\section{Publisher's Note}

Springer Nature remains neutral with regard to jurisdictional claims in published maps and institutional affiliations.
Ready to submit your research? Choose BMC and benefit from:

- fast, convenient online submission

- thorough peer review by experienced researchers in your field

- rapid publication on acceptance

- support for research data, including large and complex data types

- gold Open Access which fosters wider collaboration and increased citations

- maximum visibility for your research: over $100 \mathrm{M}$ website views per year

At BMC, research is always in progress.

Learn more biomedcentral.com/submissions 